\title{
P04-2-60 Poster session
}

\section{Potentiating effect of prostaglandin $F_{2} \alpha$ on platelet aggregation in mice}

\author{
Hitoshi Kashiwagi ${ }^{1}$, Koh-Ichi Yuhki ${ }^{1}$, Yoshitaka Imamichi ${ }^{1}$, Fumiaki Kojima ${ }^{2}$, Shima Kumei ${ }^{1}$, \\ Shuh Narumiya ${ }^{3}$, Fumitaka Ushikubi ${ }^{1}$ \\ ${ }^{I}$ Department of Pharmacology, Asahikawa Medical University, Japan, ${ }^{2}$ Department of Pharmacology, Kitasato \\ University School of Allied Health Sciences, Japan, ${ }^{3}$ Department of Drug Discovery Medicine, Kyoto University \\ Graduate School of Medicine, Japan
}

Background: Platelets play an important role in both physiological hemostasis and pathological thrombosis. Among prostanoids, consisting of prostaglandins $\left(\mathrm{PGs}\right.$ ) and thromboxane (TX), $\mathrm{TXA}_{2}$ and $\mathrm{PGI}_{2}$ are well known as a potent stimulator and an inhibitor of platelets, respectively. Recently, $\mathrm{PGE}_{2}$ has also been reported to regulate platelet function via the $\mathrm{PGE}_{2}$ receptor subtypes. However, the effect of $\mathrm{PGF}_{2} \alpha$ on platelet function remains to be determined. Here we examined the effect of $\mathrm{PGF}_{2} \alpha$ on platelet aggregation.

Methods: We used male mice lacking the prostanoid receptor: $\mathrm{PGF}_{2} \alpha$ receptor $\mathrm{FP}, \mathrm{PGE}_{2}$ receptor subtype $\mathrm{EP}_{3}$, $\mathrm{TXA}_{2}$ receptor TP and both $\mathrm{EP}_{3}$ and TP. Wild-type (WT) mice were used as a control of these mice. We prepared platelets from these mice and assessed platelet aggregation by light transmission aggregometry. In vivo, we measured bleeding time to examine the effect of $\mathrm{PGF}_{2} \alpha$ on hemostasis. Moreover, the effect of $\mathrm{PGF}_{2} \alpha$ on thrombosis was evaluated in an arachidonic acid-induced acute thromboembolism model.

Results: In WT platelets, $\mathrm{PGF}_{2} \alpha$ potentiated adenosine diphosphate (ADP)-induced aggregation in a concentrationdependent manner, while $\mathrm{PGF}_{2} \alpha$ alone did not induce aggregation. In platelets lacking $\mathrm{FP}$, however, the potentiating effect of $\mathrm{PGF}_{2} \alpha$ on ADP-induced aggregation was not significantly different from that in WT platelets. Interestingly, the potentiating action of $\mathrm{PGF}_{2} \alpha$ was significantly blunted in platelets lacking $\mathrm{EP}_{3}$ or $\mathrm{TP}$, and completely disappeared in platelets lacking both $\mathrm{EP}_{3}$ and TP. Intravenously administered $\mathrm{PGF}_{2} \alpha$ significantly shortened the bleeding time and increased mortality in an arachidonic acid-induced acute thromboembolism model in WT mice, suggesting that $\mathrm{PGF}_{2} \alpha$ acts as a platelet stimulator also in vivo.

Conclusions: $\mathrm{PGF}_{2} \alpha$ potentiates platelet aggregation via $\mathrm{EP}_{3}$ and $\mathrm{TP}$, but not via FP. Accordingly, $\mathrm{PGF}_{2} \alpha$ is involved in hemostasis and thrombosis in mice. 